\title{
BRIEF \\ Influence of Physical Education on Moderate-to-Vigorous Physical Activity of Urban Public School Children in St. Louis, Missouri, 2011-2014
}

\author{
Susan B. Racette, PhD; Tiffany C. Dill, OTD, MPH; M. Leanne White, EdS; \\ Jacqueline C. Castillo, PT, DPT, MSCl; Mary L. Uhrich, MS; Cindi L. Inman, MS, RD, LD; \\ Nicholas C. DuPont, MS; B. Ruth Clark, PT, PhD
}

\begin{abstract}
Suggested citation for this article: Racette SB, Dill TC, White ML, Castillo JC, Uhrich ML, Inman CL, et al. Influence of Physical Education on Moderate-to-Vigorous Physical Activity of Urban Public School Children in St. Louis, Missouri, 2011-2014. Prev Chronic Dis 2015;12:140458. DOI: http://dx.doi.org/10.5888/ pcd12.140458.
\end{abstract}

\section{PEER REVIEWED}

\section{Abstract}

We quantified the moderate-to-vigorous physical activity (MVPA, heart rate $\geq 140 \mathrm{bpm}$ ) of urban public elementary school children on school days with and school days without physical education (PE) class by using continuous heart rate monitoring. The heart rate of 81 students ( $93.8 \%$ black) in grades 3 and 5 was recorded in 15 -second intervals. On the basis of 575 school-day observations (mean 7.1 days/student), students accumulated 44.4 (standard deviation [SD], 34.4) minutes of MVPA on days with PE and 30.6 (SD, 29.9) MVPA minutes on days without PE $(P<.001)$. School policies should promote daily PE to help children in underresourced areas achieve the recommended 60 minutes per day of MVPA.

\section{Objective}

Physical Activity Guidelines for Americans (1) recommends that school-aged children engage in 60 minutes of physical activity daily, most of which should be moderate-to-vigorous physical activity (MVPA) because of its benefits to fitness, body composition, and metabolic health. However, children achieve on average only 30 MVPA minutes daily (2), and US children are less physically active than children in other countries (3). Urban children are particularly susceptible to inadequate physical activity (4). Physical education (PE) and recess provide MVPA opportunities in school, but policies vary widely (5). Currently, only 16 US states specify PE time requirements and only 9 states require recess in elementary schools. The aim of our study was to determine the contribution of PE class to the MVPA of urban public school children by using continuous heart rate monitoring.

\section{Methods}

This observational, cross-sectional study was conducted during 3 school years (2011-2012, 2012-2013, and 2013-2014) at 4 urban public elementary schools in St. Louis, Missouri, with 95\% student eligibility for the National School Lunch Program. Participants in grades 3 and 5 gave oral assent, and parents and guardians gave written consent. This study was approved by the Washington University School of Medicine Institutional Review Board and the school district's Research Review Committee.

Heart rate was monitored continuously and recorded every 15 seconds using Polar E600 heart rate monitors (Polar Electro) during the school day for 1 to 4 school weeks from November through April. Each heart rate value was categorized as PE class, recess, lunch, or remainder of the school day and was based on the time associated with each heart rate value and each classroom's daily schedule. PE classes were 50 minutes, once or twice each week. Recess occurred daily for 15 to 20 minutes, either outside (weather permitting) or inside (gymnasium or classroom). Each school day was coded as a PE day or non-PE day. Data on 81 students from the 4 schools and 3 school years were combined, and analyses were performed on the aggregate sample. All students had heart rate data for PE days and non-PE days. 
Primary outcomes were MVPA minutes on days with PE class and days without PE and the proportion of time spent in MVPA during PE and recess. MVPA was defined as a heart rate at or above 140 beats per minute (bpm) (6); the proportion of time in MVPA was computed by dividing the number of 15 -second heart rate values at or above $140 \mathrm{bpm}$ by the total number of 15 -second heart rate values during that segment of the school day. As a quality control measure, heart rate values lower than $50 \mathrm{bpm}$ and greater than $215 \mathrm{bpm}$ were excluded from analysis (7).

Additional outcomes included resting heart rate, estimated by averaging the 4 lowest consecutive heart rate values during classroom time each day; daily in-school steps quantified using Omron HJ-151 pedometers (Omron Healthcare, Inc) to complement the heart-rate data; body mass index (BMI) percentiles computed from measured weights and heights; and aerobic fitness estimated with the FITNESSGRAM 20-meter Progressive Aerobic Cardiovascular Endurance Run (8).

Generalized estimating equations with an exchangeable correlation matrix were used to evaluate the influence of PE class on daily in-school MVPA (determined by heart rate monitoring) and to compare the proportion of time in MVPA during PE and recess (SAS version 9.3, SAS Institute Inc). Pedometer step counts on days with and days without PE were compared by using analysis of variance.

\section{Results}

Participants were 81 students ( $57 \%$ boys, $93.8 \%$ black) in grades 3 and 5 with a mean age of 10.5 years (SD, 1.0 y). Based on BMI, $11.3 \%$ of students were overweight and $17.5 \%$ were obese. Low aerobic fitness was observed among $26.3 \%$ of students, with a difference $(P=.01)$ between the proportion of boys (15.6\%) and girls $(40.0 \%)$ who did not achieve the FITNESSGRAM Healthy Fitness Zone.

We obtained 575 days of heart rate observations (mean, 7.1 school days per student; SD, 3.5 days); 229 were school days with PE class, and 346 were school days without PE. Median heart rate values were $128 \mathrm{bpm}$ during PE class, $115 \mathrm{bpm}$ during recess, 109 bpm during lunch, and $101 \mathrm{bpm}$ during the remainder of the school day. Resting heart rate was $77 \mathrm{bpm}$.

The average number of in-school MVPA minutes was greater on days with $\mathrm{PE}$ (44.4 min; SD, $34.4 \mathrm{~min}$ ) than on days without PE (30.6 min; SD, $29.9 \mathrm{~min}, P<.001$ ) (Figure). On average, students accumulated 17.1 MVPA minutes (SD, $9.9 \mathrm{~min}$ ) during a 50minute PE class (range, 0.0-40.8 min). Recess contributed an av- erage 5.5 MVPA minutes (SD, $6.0 \mathrm{~min}$ ) each school day, with no difference between days with and days without PE $(P=.53)$. The proportion of time spent in MVPA was 38.3\% (SD, $21.7 \%$ ) during $\mathrm{PE}$ class and $27.9 \%$ (SD, 28.0\%) during recess $(P=.001)$.

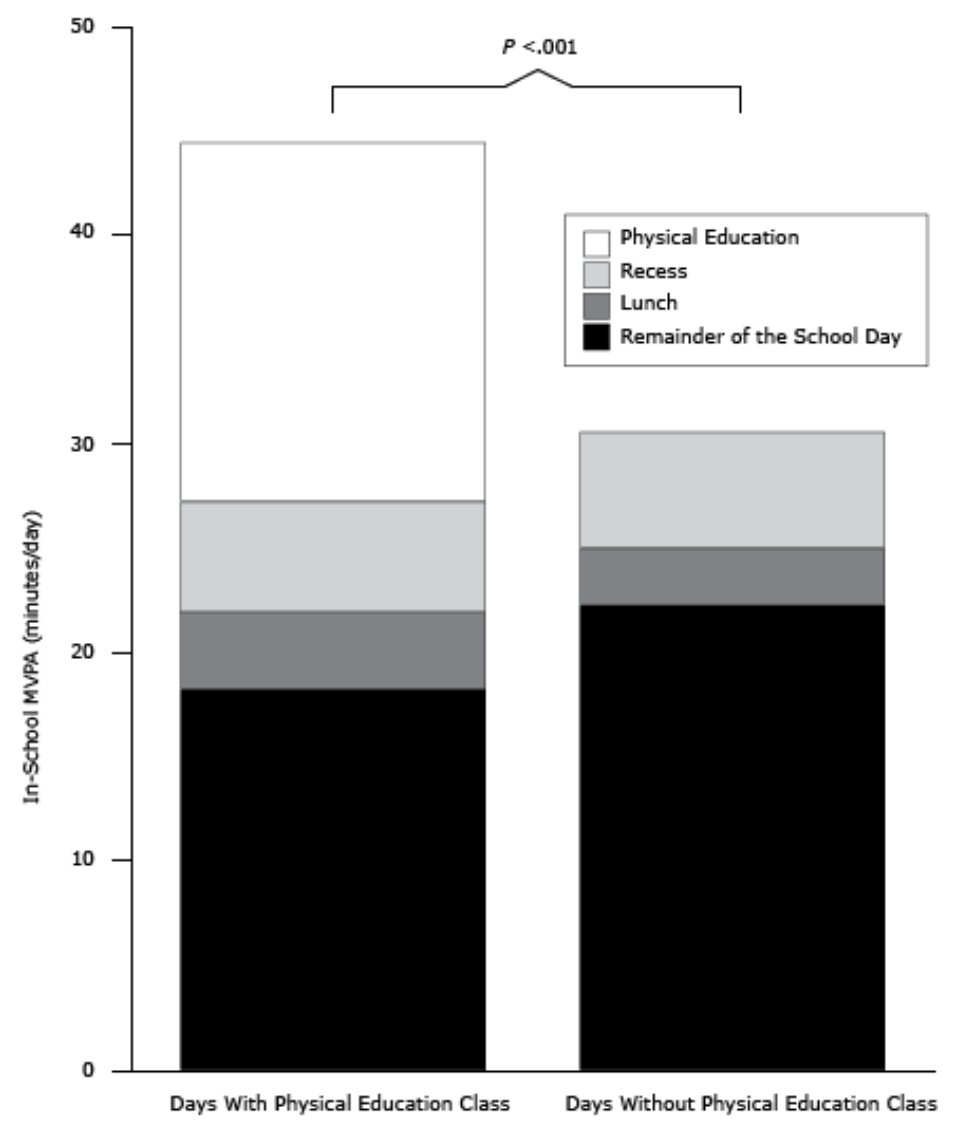

Figure. Moderate-to-vigorous physical activity (MVPA) of urban public school children in St. Louis, Missouri, 2011-2014, during several school days. Average minutes of in-school MVPA (defined as heart rate $\geq 140 \mathrm{bpm}$ ) were computed from 15-second heart rate values of 81 elementary school students. There were 229 observations on school days with physical education (PE) class and 346 observations on school days without PE class. The $P$ value compares total minutes of MVPA on school days with PE class and school days without PE class. Abbreviations: MVPA, moderate-to-vigorous physical activity; PE, physical education.

The influence of PE on MVPA minutes was similar for boys and girls $(P=.82$ for $P E$ by sex interaction) and across schools $(P=$ .65 for PE by school interaction), but was greater for 5 th grade than for 3 rd grade students ( $P=.04$ for PE by grade interaction). Pedometer step counts indicated greater physical activity on days with PE class (4,437 steps/d; SD, 2,477 steps) than on days without PE class $(3,628$ steps/d; SD 1,695 steps, $P<.001)$.

\footnotetext{
The opinions expressed by authors contributing to this journal do not necessarily reflect the opinions of the U.S. Department of Health and Human Services, the Public Health Service, the Centers for Disease Control and Prevention, or the authors' affiliated institutions.
} 


\section{Discussion}

The major finding of this study was that PE class and recess provide opportunities for urban elementary school children to engage in MVPA during the school day. Racial/ethnic minority children residing in low-resource areas may benefit the most from school-based opportunities for MVPA. Our observation that less than $40 \%$ of PE class time was spent in MVPA is consistent with previous findings among 3rd grade students across 10 cities (9) and highlights the need for PE classes to be held more than once or twice each week.

Our results support recent recommendations (10) that the US Department of Education designate PE as a core curricular subject. Nationwide reductions in PE occurred as a consequence of the No Child Left Behind legislation (10). Importantly, both physical activity and physical fitness have been associated with greater academic achievement in several studies $(11,12)$. A 2013 Cochrane Review (13) highlighted the benefits of school-based physical activity initiatives on increasing MVPA and fitness.

The White House Task Force on Childhood Obesity (14) identified "increasing physical activity" as one of 4 priority areas for enhancing child health. Notable recommendations are to increase the quality and frequency of PE and to promote recess for elementary school students. The Institute of Medicine (10) and an expert panel of the National Heart, Lung, and Blood Institute (15) recommended that elementary schools offer PE daily. Our results support these recommendations.

Limitations of this study are that heart rate was monitored during the school day only, and the sample was limited to 81 students in 4 schools. Strengths include the 15 -second heart rate sampling periods as an index of physical activity intensity and the large number of sampling days.

In summary, physical education and recess provide essential opportunities for urban, racial/ethnic minority children to engage in physical activity of moderate or vigorous intensity during the school day. School policies should endorse daily PE and recess in elementary schools to facilitate achievement of MVPA goals.

\section{Acknowledgments}

This research was supported by the Washington University Institute of Clinical and Translational Sciences grant no. UL1 TR000448 and subaward no. TL1 TR000449 from the National Center for Advancing Translational Sciences of the National Institutes of Health and the St. Louis Community/University Health Research Partnerships grant sponsored by Washington University,
Saint Louis University, and BJC HealthCare. We thank students, teachers, and administrators at participating Saint Louis Public Schools and Karen Steger-May for her biostatistical expertise.

\section{Author Information}

Corresponding Author: Susan B. Racette, PhD, Professor, Washington University School of Medicine, Campus Box 8502, 4444 Forest Park Ave, St. Louis, MO 63108. Telephone: 314-2861424. Email: racettes@wustl.edu.

Author Affiliations: Tiffany C. Dill, Jacqueline C. Castillo, Mary Uhrich, Cindi L. Inman, Nicholas C. DuPont, B. Ruth Clark, Washington University School of Medicine, St. Louis, Missouri; M. Leanne White, St Louis Public Schools, St. Louis, Missouri.

\section{References}

1. Subcommittee of the President's Council on Fitness, Sports and Nutrition. Physical Activity Guidelines for Americans midcourse report: strategies to increase physical activity among youth. Washington (DC): US Department of Health and Human Services; 2012.

2. Epstein LH, Paluch RA, Kalakanis LE, Goldfield GS, Cerny FJ, Roemmich JN. How much activity do youth get? A quantitative review of heart-rate measured activity. Pediatrics 2001;108(3):E44.

3. Beets MW, Bornstein D, Beighle A, Cardinal BJ, Morgan CF. Pedometer-measured physical activity patterns of youth: a 13country review. Am J Prev Med 2010;38(2):208-16.

4. Johnson TG, Brusseau TA, Darst PW, Kulinna PH, WhiteTaylor J. Step counts of non-white minority children and youth by gender, grade level, race/ethnicity, and mode of school transportation. J Phys Act Health 2010;7(6):730-6.

5.2012Shape of the Nation Report: status of physical education in the USA. National Association for Sport and Physical Education and American Heart Association. http:// www.aahperd.org/naspe/publications/upload/2012-Shape-ofthe-Nation-Quick-Facts.pdf. Accessed July 24, 2014.

6. Armstrong N, Welsman JR, Kirby BJ. Longitudinal changes in 11-13-year-olds' physical activity. Acta Paediatr 2000; 89(3):775-80. Pub7Med

7. Jago R, McMurray RG, Bassin S, Pyle L, Bruecker S, Jakicic JM, et al. Modifying middle school physical education: piloting strategies to increase physical activity. Pediatr Exerc Sci 2009;21(2):171-85.

8. Meredith MD, Welk GJ, editors. FitnessGram and ActivityGram test administration manual. 4th ed. Dallas (TX): The Cooper Institute; 2010.

The opinions expressed by authors contributing to this journal do not necessarily reflect the opinions of the U.S. Department of Health and Human Services, the Public Health Service, the Centers for Disease Control and Prevention, or the authors' affiliated institutions. 
9. Nader PR,National Institute of Child Health and Human Development Study of Early Child Care and Youth Development Network. Frequency and intensity of activity of third-grade children in physical education. Arch Pediatr Adolesc Med 2003;157(2):185-90.

10. IOM (Institute of Medicine). Educating the student body: taking physical activity and physical education to school. Washington (DC): The National Academies Press; 2013. http:// www.iom.edu/Reports/2013/Educating-the-Student-BodyTaking-Physical-Activity-and-Physical-Education-toSchool.aspx. Accessed July 24, 2014.

11. Castelli DM, Hillman CH, Buck SM, Erwin HE. Physical fitness and academic achievement in third- and fifth-grade students. J Sport Exerc Psychol 2007;29(2):239-52.

12. Rasberry CN, Lee SM, Robin L, Laris BA, Russell LA, Coyle $\mathrm{KK}$, et al. The association between school-based physical activity, including physical education, and academic performance: a systematic review of the literature. Prev Med 2011;52(Suppl 1):S10-20.

13. Dobbins M, Husson H, DeCorby K, LaRocca RL. Schoolbased physical activity programs for promoting physical activity and fitness in children and adolescents aged 6 to 18 . Cochrane Database Syst Rev 2013;2:CD007651.

14. Solving the problem of childhood obesity within a generation. White House Task Force on Childhood Obesity Report to the President; 2010 http://www.letsmove.gov/sites/letsmove.gov/ f $\quad$ i $\quad 1 \quad$ e $\quad$ s $/$ TaskForce_on_Childhood_Obesity_May2010_FullReport.pdf. Accessed July 24, 2014.

15. Expert Panel on Integrated Guidelines for Cardiovascular Health and Risk Reduction in Children and Adolescents. Summary report. US Department of Health and Human Services, National Institutes of Health, National Heart, Lung, and Blood Institute, 2012. http://www.nhlbi.nih.gov/ guidelines/cvd_ped/peds_guidelines_sum.pdf. Accessed July 24, 2014.

\footnotetext{
The opinions expressed by authors contributing to this journal do not necessarily reflect the opinions of the U.S. Department of Health and Human Services, the Public Health Service, the Centers for Disease Control and Prevention, or the authors' affiliated institutions.
} 